\title{
Seignobos x Simiand: a querela do método histórico com a ciência social no início do século XX
}

Seignobos x Simiand: the quarrel of the historical method with social science in the early twentieth century

\author{
Rafael Nascimento Gomes ${ }^{*}$
}

\section{Resumo}

Este artigo tem por objetivo analisar a querela travada no início do século XX, na França, mas que teve repercussões para além do hexágono, entre as ciências História e Ciência Social, especificamente, a querela do método histórico com a ciência social, isto é, entre o historiador Charles Seignobos (18541942) e o sociólogo e economista François Simiand (1836-1935). O embate intelectual entre Seignobos e Simiand está inserido em um processo maior de institucionalização e profissionalização dessas áreas do conhecimento. Portanto, a partir desse contexto sociointelectual francês, pretende-se explorar o debate entre o método histórico, proposto pela chamada Escola Metódica, liderada por Seignobos, e a Ciência Social, que buscava ganhar espaço acadêmico-institucional, representada por Simiand.

Palavras-chave: Historiografia; Escola Metódica; Charles Seignobos; François Simiand.

\begin{abstract}
This article aims to analyze the quarrel at the beginning of the twentieth century in France, but which had repercussions beyond the hexagon, between the Sciences History and Social Science, specifically the quarrel of the historical method with social science, between the historian Charles Seignobos (1854-1942) and the economist and sociologist François Simiand (1836-1935). The intellectual clash between Seignobos and Simiand is part of a larger process of institutionalization and professionalization of these areas of knowledge. Therefore, from this French socio-intellectual context, we intend to explore the debate between the historical method, proposed by the so-called Methodical School, led by Seignobos, and Social Science, which sought to gain academic-institutional space, represented by Simiand.
\end{abstract}

Keywords: Historiography; Methodical School; Charles Seignobos; François Simiand.

\section{Introdução}

É espantoso e injusto notar que ao longo de anos de formação em História, somente na pós-graduação, alguns poucos alunos têm contato com os historiadores franceses Charles-Victor Langlois (1863-1929) e Charles Seignobos (1854-1942), seja do ponto de vista historiográfico, seja teórico. Esses dois importantes pensadores da

\footnotetext{
* Doutorando em História pelo Programa de Pós-Graduação da Universidade de Brasília (UnB). Membro do Núcleo de Estudos Latino-Americanos da Universidade de Brasília (IREL/UnB).
} 
disciplina, que no final do século XIX sistematizaram o método histórico em um manual de intensa disseminação pela França, Introdução aos Estudos Históricos, responsável pela formação de inúmeras gerações de historiadores e professores, inclusive no Brasil, a partir da tradução de Laerte de Almeida de Morais para o português pela Editora Renascença, de São Paulo, em 1946. Por outro lado, considerando a História como uma ciência social, é de extrema estranheza a atenção pouco dada para o sociólogo e economista François Simiand (1836-1935), que bem ou mal, inspirou a comunidade de intelectuais, tanto historiadores como sociólogos, ou até mesmo geógrafos e filósofos, a se debruçarem sobre o método das ciências humanas.

No final do século XIX e início do XX, Seignobos, com a ajuda de outros historiadores, participou de um grande esforço voltado para sistematizar métodos e procedimentos relacionados à História de modo a estabelecer as fronteiras do fazer historiográfico. Era o momento de institucionalização e profissionalização da História como ciência, em especial, na Alemanha e na França. Sua preocupação com o tratamento das fontes e documentos históricos notabilizou a contribuição da chamada Escola Metódica, muitas vezes chamada injustamente de "Escola Positivista". Nesse sentido, acompanhando o desenvolvimento da busca da cientificidade em diversos ramos do conhecimento, a História conheceu uma grande transformação resultante da intenção de seus escritores de elevá-la ao estatuto de ciência, a exemplo do que ocorria com o conhecimento da natureza, apoiado em métodos críticos voltados para a obtenção do conhecimento objetivo, livre do pensamento mítico, religioso ou filosófico.

E é nesse contexto que o positivismo, postulado por Augusto Comte (17981857), estabeleceu um paradigma da busca da verdade calcado na convicção da existência de leis naturais e afirmou a possibilidade de sua aplicação ao estudo da sociedade. Assim como à nascente Sociologia, cabia à História procurar resgatar a verdade objetiva, imparcial e neutra sobre o passado, utilizando, para isso, as provas documentais deixadas pelos nossos antecessores. Desse modo, a base documental da pesquisa histórica firmou-se, desde então, com a abordagem metodológica que considerava os documentos escritos - sobretudo os oficiais -, registros confiáveis da experiência humana. Uma vez aprovadas em matéria de confiabilidade, as chamadas fontes históricas eram estudadas pelo historiador no sentido do resgate de informações sobre o passado "como realmente aconteceu" (MALATIAN, 2012, p. 61-68).

Nesse ambiente, constituiu-se, na França, a chamada Escola Metódica que codificou esses postulados de cientificidade e os apresentou como regras de método de 
trabalho para o historiador. Um de seus principais defensores foi Gabriel Monod (18441912), que escreveu em seu Manifesto a frase célebre: "Nosso século é o século da história". Para bem alcançar a objetividade histórica, Monod, em seu manifesto intitulado, "Do progresso dos estudos históricos na França desde o século XVI", propunha uma historiografia que deveria colocar-se acima dos partidos políticos, publicando estudos históricos sem preconceitos, conciliadores e estritamente norteados pelo desejo de conhecimento científico (MALATIAN, 2012, p. 61-68).

Nesse sentido, a evolução decisiva para a historiografia deu-se com o que se pode chamar de fundamentação metódico-documental, basilar para a disciplina "acadêmica" contemporânea. Tem-se aqui, para Estevão Martins, a origem da grande corrente historiográfica que se chamou - de forma exagerada - de historiografia "positivista", intimamente entrelaçada à forte tradição do historicismo alemão ${ }^{1}$ (MARTINS, 2010, p. 11-12.) Como se pode observar, a qualificação "positivista” ainda é muito utilizada, contudo, no sentido estritamente pejorativo. Por isso, é preciso que esses textos clássicos da historiografia, tal como os de Langlois e Seignobos e os de Simiand, sejam revistos e reavaliados, criticamente, por estudantes, seja da graduação, seja da pós-graduação. Na verdade, devem ser lidos como documentos históricos da virada do século e como esforços de se pensar a teoria e o método da nossa disciplina.

Essa reflexão definiu os parâmetros metódicos estipulados como obrigatórios para que a História se enquadrasse no que se tinha, então, por padrão de "ciência". é a razão pela qual inúmeros tratadistas tomaram como referência específica do estudo de História a ciência natural. Normatizar os procedimentos para obter algum grau de densidade confiável era percebido como uma missão que levou à produção de textos metodológicos famosos, sobretudo na França e na Alemanha, de Buchez e Lacombe, de Ranke, de Droysen e de Bernheim, chegando a Langlois-Seignobos e a Lamprecht (MARTINS, 2010, p. 11-12). Aqui, analisaremos apenas um deles: Introduction aux études historiques (1898) de Langlois e Seignobos. Todavia, outros textos de Seignobos também serão perscrutados, como La méthode historique apliquée aux sciences sociales (1901), além dos trabalhos de Simiand, Méthode historique et Science sociale (1903), e

\footnotetext{
${ }^{1}$ É fácil compreender como a Alemanha pode aparecer aos olhos dos historiadores franceses, no início da década de 1870, como uma espécie de terra prometida da história. Sem dúvida, cada um deles se empenha em também achar defeitos no sistema alemão (DELACROIX, 2012, p. 79).

2 Cabe lembrar que naquele momento, o padrão de ciência, em grande medida, era tido a partir dos "modelos científicos" das ciências naturais.
} 
Note de méthode: Sur la notion de cause en matière historique et sociologique (1903b), textos de enfrentamento ao método histórico proposto pelos historiadores.

\title{
O contexto sociointelectual francês
}

Antes de abordar o embate entre a História e as Ciências Sociais no início do século XX, a partir de Seignobos e Simiand, faz-se necessário contextualizar, brevemente, o cenário sócio-político e intelectual da França. Já no final da década de 1860, o movimento de renovação da historiografia pode ser percebido em diversos movimentos. E é nesse período que são definidas as qualidades que o historiador deve ter: modéstia, prudência, erudição, recusa das paixões (DELACROIX, 2012, p. 83).

François Dosse destaca que a verdadeira idade de ouro dos historiadores da França situa-se depois da derrota de Sedan, após a amputação da Alsácia e da Lorena. Disso resulta uma conjunção excepcional entre a mobilização dos historiadores em vista da profissionalização e as exigências de reconquista da integridade territorial da nação. Nas palavras de Dosse:

\begin{abstract}
Até os anos de 1880 a disciplina histórica ainda não tem verdadeira autonomia universitária, dependendo tanto da filosofia quanto das humanidades literárias. A conta dessa data, cria-se uma licença específica para o ensino de história ${ }^{3}$, e o ofício do historiador se profissionaliza. Entre 1870 e 1914, a história beneficia-se do maior número de novas cátedras universitárias. Os historiadores de formação, em busca de uma identidade específica, passam a propor regras de método, rompendo radicalmente com o amadorismo vigente até então. Essa identidade afasta-se do terreno literário. (DOSSE, 2001, p. 16-17).
\end{abstract}

É nesse contexto que, a partir de 1890, Charles Seignobos é encarregado de uma disciplina na Sorbonne dedicada à pedagogia das ciências históricas e, com CharlesVictor Langlois, escreve uma obra que logo tornou-se obrigatória para todo estudante de História, Introduction aux études historiques, publicada em 1898. Os autores definem estritamente as regras do método historiográfico que deve proceder as duas críticas das fontes: uma crítica externa, chamada erudita, e uma crítica interna, que opera por meio de raciocínio e analogia. O respeito pelo documento histórico e o controle da

\footnotetext{
${ }^{3} \mathrm{O}$ grande mestre que vai reinar sobre o ensino de história naquele final do século XIX e início do século XX é Ernest Lavisse. Aliando preocupação metódica e pedagógica, Lavisse organizou a monumental Histoire de France publicada pela Hachette, resultado de um trabalho coletivo de vinte anos desde a assinatura do contrato (1892) até a publicação do último volume (1911). Lavisse encarna uma verdadeira republicanização da memória. Extrapolando o âmbito universitário, ele se torna o professor de toda a nação e para a nação. Seu sucesso é tal que se cria o manual Lavisse, chamado de Petit Lavisse, no qual todas as crianças da escola pública logo aprenderão a história de sua nação (DOSSE, 2001, p. 18).
} 
subjetividade são também as regras de ouro daquilo que passará a se chamar escola metódica. Mais tarde, ela será de algum modo vituperada e caricaturada pela escola dos Annales, com a denominação de história historicizante (DOSSE, 2001, p. 16-17).

No entanto, é importante destacar que a ascensão das Ciências Sociais, no final do século XIX, conduz a História e a sociologia durkheimiana a disputarem a hegemonia em termos de cargos universitários. E, em 1894, o historiador Pierre Lacombe atribuiu à História uma perspectiva sociológica: a busca de leis. Nesse sentido, os historiadores deveriam deixar de lado o acontecimento singular para trabalhar com as regularidades. Para responder a Lacombe, Charles Seignobos escreve O método histórico aplicado às ciências sociais, insistindo no fato de que a comparação (própria ao método sociológico) permite a analogia, mas não a similitude total. (MALERBA, 2010, p.379-380). Nesse texto, Seignobos precisa algumas concepções fundamentais:

a. A história não é uma ciência exata, ela é um "conhecimento através de rastros", ou seja, ela nunca provém de uma observação direta. Ele distingue rastros materiais e o que ele chama de rastros psicológicos. Os documentos não correspondem ao real, mas a abstrações, pois são rastros que exprimem a psicologia de seus autores, que são imagens e representações.

b. A imaginação controlada do historiador é o suporte de sua construção, uma vez que é impossível aplicar à História os métodos de outras ciências;

c. Ao contrário da sociologia durkheimiana, as realidades sociais são, por essência, subjetivas. Em razão da particularidade dos fenômenos históricos, é impossível a adoção de uma abordagem quantitativa.

Por conta disso, a "Escola Metódica" foi vista durante décadas como "positivista", fundamentalmente pedagógica e nacionalista, ignorando sua própria construção e afirmando a objetividade da História. Em outras palavras, ela seria, segundo Lucien Febvre, a história a ser rejeitada, ou seja, "a sua própria negação". Distanciando-se do "providencialismo cristão", do "progressismo racionalista" e até mesmo do "finalismo marxista", a história metódica teria como principal objetivo não a elaboração do conhecimento, mas pôr em prática os documentos. A concepção restrita de documentos (fontes unicamente escritas) limitaria a ambição da disciplina. Pretendendo atingir a imparcialidade e a objetividade, essa ciência histórica se 
apresentava como um discurso ideológico, servindo aos interesses de um regime político e manifestando, por consequência, as aspirações de uma comunidade nacional. Denominada "história positivista", essa corrente teria por ambição transformar a História em instrumento de uma educação cívica, aliada à propaganda nacionalista e à Terceira República francesa ${ }^{4}$. (MALERBA, 2010, p. 375).

Nesse sentido, o alerta feito pelo professor Estevão Martins ganha evidência. Segundo ele, a escola que, erroneamente, era chamada de "positivista" pode ser também denominada - com mais propriedade - de "escola metódica", já que a sua principal preocupação era de dispor de um método. Essa escola, que fundamentava o progresso da historiografia no trabalho metódico das fontes, sempre foi avessa a qualquer "teoria" ou "filosofia". Trata-se, antes de mais nada, de uma corrente pragmática e empirista. Por isso, pode ser chamada de escola pragmático-documental ou metódico-documental (MARTINS, 2010, p. 12).

Contudo, é importante também reconhecer a dimensão política dada à História. Desse ponto de vista, a escola metódica é realmente a historiografia dos republicanos governamentais, isto é, aqueles que se empenham em praticar uma política do possível que alie princípios e pragmatismo. ${ }^{5}$ Tendo os historiadores metódicos muito a oferecer à República, esta se mostra generosa para com eles e permite, para garantir a estabilidade política, que até a historiografia se estabilize. A hora é da profissionalização dos historiadores franceses. Nesse contexto, portanto, é que aparece o mais famoso manual da escola metódica, Introduction aux Études Historiques, ${ }^{6}$ celebrizado pelo estigma de conservadorismo que recebeu dos historiadores que fundaram a escola dos Annales, como enfatizou José D’Assunção Barros. Esse texto retira do manual historicista de Bernheim a sua reflexão inicial sobre a filosofia da história de sua época para aceitar apenas a parte prática, metodológica (BARROS, 2010, p. 82).

Além desse aspecto descritivo, que define até o estilo que convém ao historiador, Langlois e Seignobos tentam reconstituir o conjunto das etapas da

\footnotetext{
${ }^{4}$ Com a Terceira República, no final do século XIX, a Revolução Francesa tornou-se objeto de estudo. É criado um curso na Sorbonne, em 1886, dirigido por Albert Mathiez.

5 Naquele momento, o nacional transcendeu as dilacerações políticas e sociais, e a primeira tarefa do historiador foi evidenciar essa continuidade nacional. Nesse sentido, a República é o fruto maduro do movimento da história da França; o passado monárquico, sua infância; diminuir um em nome do outro é, portanto, tão inconcebível como querer voltar atrás. Esse é exatamente o discurso de que os republicanos oportunistas, que triunfaram em 1879, precisaram para fundamentar a ideia de que a República é o regime natural da França.

${ }^{6}$ Esse manual foi um trabalho em conjunto entre Charles-Victor Langlois e Charles Seignobos, publicado na França, em 1898, e traduzido para o português somente, em 1946, pela Editora Renascença.
} 
elaboração da História. Começam por expor a pesquisa das fontes, depois passam à apresentação das diversas críticas. A crítica externa ou de erudição determina a autenticidade do documento, define sua origem e permite datá-lo ao recorrer às disciplinas auxiliares. É uma condição necessária à História. A Introduction dá conta das exigências do momento sobre a classificação das fontes e prega uma divisão do trabalho entre os eruditos encarregados de estabelecer os textos e os historiadores que devem explorá-los. Ao fazer isso, esse livro define uma deontologia - uma ética da história - e uma epistemologia. (MALERBA, 2010, p. 28).

Nesse momento, nos anos 1890-1910, a história metódica entra em uma zona de turbulência. Encontra-se aprisionada entre dois fogos: de um lado, os que censuram o seu culto à objetividade e a sua fraqueza em considerar os processos específicos do conhecimento histórico; de outro, os que denunciam seu demasiado enraizamento no particular e no individual, por conseguinte, gerando um déficit científico. Em ambos os casos, é a definição largamente empírica das práticas históricas que é derrubada. $\mathrm{Na}$ Alemanha, o debate se inicia nos anos 1890. Ele opõe, de um lado, os que são favoráveis à uma mutação científica da História, que deveria se operar - mais ou menos - a partir do modelo das ciências da natureza, considerando (de vários modos) a noção de coerção, quer para construir as leis do devir histórico (Karl Marx), quer para definir os tipos ideais (Max Weber); de outro lado, aqueles que definem a História como ciência do espírito (Wilhem Dilthey) (MALERBA, 2010, p. 28).

Como destacou Guilherme Pereira das Neves, a situação de tensão no campo epistemológico parece recorrente. No ambiente em que foram gestados os Annales, a virada do século XIX para o XX, conflitos semelhantes voltam a emergir. De um lado, estão as tensões que perpassam naquela ocasião o surgimento da própria Sociologia, analisadas por Wolf Lepenies; de outro, quando François Simiand investe em 1903 contra Charles Seignobos, é impossível esquecer que a crise da história na França da belle époque encontra uma sincronia temporal quase perfeita com o que acontecia em outras regiões. Na Inglaterra, a oposição entre a concepção um tanto ingênua de John B. Bury da História como uma ciência, e aquela de George Macaulay Trevelyan, como uma musa. No mundo de língua alemã, o Methodenstreit entre o economista austríaco Carl Menger, com importante contribuição para a teoria da utilidade marginal, e o economista-historiador Gustav von Schmoller; como também o enfrentamento entre a perspectiva mais abrangente, capaz de contemplar aspectos sociais e econômicos, ainda que frágil, de Karl Lamprecht, e aquela dos historiadores, como Friedrich Meinecke, 
voltada para a política e as ideias que orbitavam em torno do Historische Zeitschrift. Na Itália, o debate entre Gaetano Salvemini e Benedetto Croce nas páginas da precursora Rivista italiana di sociologia (surgida em 1897), comentado por ninguém menos do que Émile Durkheim no 6º volume de l'Année sociologique, entre 1901 e 1902 (NEVES, 2012, p. 225-226).

No debate epistemológico, a sociologia durkheimiana queria ganhar cada vez mais espaço, e, para isso, propunha um método próprio, por sua vez, diferente do método histórico. Prost destaca que, em 1903, ao atacar Seignobos, auxiliar de Lavisse, Simiand foi malsucedido; de fato, por razões complexas - a mais insignificante das quais não foi a ausência de vínculo histórico com o ensino médio -, a Sociologia não conseguiu implantar-se, então, na universidade francesa (PROST, 2014, p. 37). De toda forma, marcou um dos mais importantes debates epistemológicos das Humanidades do início do século XX.

\section{Simiand x Seignobos: um embate entre métodos}

Como vimos acima, o método era crucial nesse debate, pois, naquele momento, somente ele era capaz de garantir a validade do saber histórico. Como destaca Antoine Prost, o prestígio granjeado na nossa sociedade pela ciência levou os historiadores - e, em sua companhia, os sociólogos e os antropólogos - a tornar seus métodos mais exigentes e a reivindicar procedimentos mais rigorosos. Eles esforçaram-se em aproximar-se do modelo de legitimidade em vigor nas ciências exatas; apesar de ter evoluído, tal modelo continuou sendo uma referência, a um só tempo, invejável e inacessível (PROST, 2014, p. 169-188).

Nesse contexto, ao pretender se tornar uma "ciência", a História circunstanciou e executou um acirrado debate com as Ciências Sociais, naquele momento em pleno processo de desenvolvimento de áreas, procedimentos, problemas e objetos de pesquisa, e esse diálogo se dava nas universidades, lugar social de onde estiveram se agrupando historiadores e cientistas sociais, com vistas a constituírem seus respectivos ofícios profissionais. $\mathrm{O}$ embate que se destacou no início do século $\mathrm{XX}$ se deu entre o sociólogo durkhaminiano, François Simiand, economista e professor do Collége de France, e Charles Seignobos, historiador e professor da Sorbonne. O problema central dessa disputa era o seguinte: em que sentido o método histórico e a ciência social conflitam-se e divergem-se? (SIMIAND, 2003, p. 27). 
Brunno Velloso Silva apresenta as quatro batalhas principais entre Simiand e Seignobos tentando responder, de alguma maneira, a esse problema: dois artigos escritos por François Simiand ataca o método histórico - o primeiro publicado em 1903, na Revue de synthèse historique, intitulado Méthode historique et science sociale e o segundo, La causalité en histoire, apresentado em 1906, na Societé Française de Philosophie, seguido de debate; e dois artigos de defesa do método histórico, de autoria de Charles Seignobos, também apresentados diante da Société Française de Philosophie, com os títulos de Les conditions pratiques de la recherche des causes dans le travail historique e L'inconnu et l'inconscient en histoire, o primeiro texto de 1907 e o segundo de 1908 (SILVA, 2014, p.10-11). Contudo, como lembrou o autor, apesar de reconhecido por seus professores e entre os membros de L'Année Sociologique como um intelectual altamente promissor, Simiand ainda não havia publicado sequer um livro e contava apenas em seu curriculum com a impressão de algumas resenhas críticas e artigos. Charles Seignobos, por sua vez, já havia atingido - assim como a História, naquele momento - um considerável nível de reconhecimento acadêmico. Seignobos concluíra seu Doctorat em 1888, tornara-se professor na Sorbonne e fazia mais de dez anos que havia impresso seu primeiro livro.

De toda forma, o historiador sofre concorrência das jovens Ciências Sociais que se desenvolvem como ciências irmãs, mas que poderiam pretender englobar a história, anexá-la em seu discurso menos ideológico e mais científico. Trata-se, sobretudo, como destacou François Dosse, do projeto explícito de uma sociologia durkheimiana conquistadora. Para conseguir autonomia em relação à Filosofia e voar com asas próprias, a Sociologia preconiza uma estratégia dinâmica de alianças com outras disciplinas em torno de conceitos mais científicos. Fortalecidos por algumas posições como a de Durkheim em Bordeaux, de Halbwachs e Gurvitch em Estrasburgo, de Marcel Mauss no Collége de France ou, ainda de Célestin Bouglé na Sorbonne, os sociólogos fundam L'Anné Sociologique em 1897, que se torna um instrumento de conquista. Acham que podem transformar-se em uma ciência de confluência, englobando uma História que teria se tornado mais "inteligente": "ao comparar, a história já não se distingue da sociologia”, dizia Durkheim. Esse desafio dos sociólogos, que, lançado aos historiadores, convida-os a questionarem radicalmente a sua identidade de antes da guerra (DOSSE, 2001, p. 19).

Nesse contexto que, em 1903, François Simiand, discípulo de Durkheim, escreveu o seu famoso artigo na revista de Henri Berr: Méthode historique et sciences 
sociales. ${ }^{7}$ Nele, o sociólogo denuncia uma história que nada tem de científica, mas um simples procedimento de conhecimento condenado à descrição de fenômenos contingentes, casuais, enquanto a sociologia pode ter acesso a fenômenos regulares e estáveis, deles deduzindo a existência de leis. Naquele momento, Simiand desferiu um ataque mortal à historiografia, condenando os chamados ídolos dos historiadores (cronológico, individual e político).

Para Dosse, Simiand denuncia, sobretudo, os três ídolos da tribo historicista: o ídolo político ("ou seja, o estudo dominante ou pelo menos a preocupação perpétua com a história política, dos fatos políticos, das guerras, etc, que chega a atribuir a esses acontecimentos uma importância exagerada"), assim como o ídolo individual e o cronológico ("ou seja, o hábito de perder-se em estudos de origens"). Para Prost, a condenação é lógica, porque a política tem a ver, por definição, com a ordem das intenções, ou seja, do psicológico, e não do social, no sentido durkheimiano; por sua vez, o individual está necessariamente excluído de uma ciência que pretende ser social (PROST, 2014, p.176). Simiand espera, assim, granjear para a sociologia um certo número de historiadores inovadores, preocupados em substituir a prática empírica por um método reflexivo, crítico, elaborado por sociólogos (DOSSE, 2001, p. 19).

Isso porque, para Simiand, sem discutir as definições mais controvertidas, a ciência social é a disciplina que estuda os fenômenos sociais, que caracterizam a vida do homem em sociedade (SIMIAND, 2003, p. 29). E os fenômenos sociais, por sua extensão e por sua natureza, defende Simiand, não podem ser alcançados pela observação indireta, restando ao cientista buscar os fatos e os casos de experiência na relação do passado da humanidade e empregar, necessariamente, o método histórico. Nesse sentido, a ciência social, à medida que recorre ao conhecimento do passado, refina-se sobre a mesma matéria ou objeto da disciplina histórica (SIMIAND, 2003, p. 29). Grosso modo, Simiand, ao criticar a História, propunha que a ciência social assumisse a função, e os espaços, da ciência vizinha. Nas palavras de Simiand:

[...] a preocupação dominante deve ser a de substituir uma prática empírica, mal refletida, por um método pensado com rigor e verdadeiramente crítico. Não acredito em uma reformulação repentina, bastando, para isso, a definição e a aceitação consensual do fim a ser atingido. Creio, entretanto, que nos trabalhos dos historiadores atuais, na escolha e no ordenamento refinado de suas pesquisas, na sua preocupação manifesta em renovar a sua obra, aproveitando-se dos progressos das disciplinas vizinhas, evidenciam-se as tendências de substituição progressiva da prática tradicional pelo estudo

\footnotetext{
${ }^{7}$ Originalmente um conjunto de conferências, depois publicadas no ano de 1903 na Revista de Síntese Histórica, então dirigida por Henri Berr, e republicadas, em 1960, na Revista Annales.
} 
positivo e objetivo do fenômeno humano, susceptível de explicação científica, e, finalmente, de elaboração consciente de uma ciência social. Conduzir o bom termo estas tendência, transformando-as em ato, será, espero, obra da nova geração (SIMIAND, 2003, p. 115-116).

Todavia, um dos principais pontos dessa querela estava na nova abordagem dos fenômenos sociais proposta pela Sociologia, inspirada nas obras de Émile Durkheim (1858-1917). Como destacou Bruno Hoffmann Velloso Silva, o que os sociólogos pareciam pretender era a derrubada de grande parte, ou melhor, da coluna central do método histórico - fundado na pesquisa de eventos considerados singulares - e sua substituição pelo princípio sociológico do fato social, que apontava para força própria dos fenômenos coletivos da sociedade (SILVA, 2014, p.8). Apoiado nas postulações de Comte sobre a existência de características próprias ao estudo dos fenômenos sociais, Durkheim procurou consolidar o campo da Sociologia. Para tanto, reafirmou e enfatizou a separação entre a Sociologia e a Psicologia. Em suas Regras do Método Sociológico, de 1894, ele apresentou um conjunto importante de pressupostos que deveriam orientar o trabalho dos sociólogos. Assim, Durkheim argumentava que os indivíduos eram guiados por forças sociais e essas eram externas a eles, as regras relativas a essas forças não poderiam ser encontradas na consciência dos indivíduos. Isto é, "pode-se estabelecer como princípio que os fatos sociais são tanto mais suscetíveis de ser objetivamente representados quanto mais completamente separados dos fatos individuais que os manifestam"(SILVA, 2014, p. 10).

Dessa maneira, a tradicional metodologia histórica e a nova metodologia sociológica pensavam a importância do indivíduo na dinâmica da vida social de forma bastante assimétrica. Se um historiador descobria as razões de uma guerra na personalidade ambiciosa de um monarca, os sociólogos poderiam facilmente supor que naquela sociedade a guerra cumpriria a função de controle populacional. Em suma, os métodos aplicados pelos sociólogos não apenas retiravam de cena o indivíduo, mas colocavam em seu lugar abstrações conceituais, que alargavam exponencialmente as ambições explicativas da Sociologia, se comparadas às da História. Com tamanho potencial para transpassar séculos e os mais variados grupos humanos, poderia se imaginar então que a Sociologia teria preponderância metodológica sobre a História, acanhada apenas em narrar eventos bem circunscritos (SILVA, 2014, p.10).

Em outras palavras, Simiand desejava que os historiadores substituíssem a relação lógica e causal dos eventos, considerados singulares, por uma análise 
sociológica, que procurasse, por meio das boas abstrações, evidenciar as regularidades e, se possível, as leis que regulavam os fenômenos sociais. No entanto, Simiand via a impossibilidade de estabelecer, por meio de relações causais singulares e individuais, regras ou leis que, de fato, explicassem a vida em sociedade.

Em resposta, Langlois e Seignobos, em Introdução aos Estudos Históricos ${ }^{8}$, declaram que pretendem solapar as ambições dos sociólogos. Para isso, sistematizam sua obra em três livros: i) "Conhecimentos prévios" (a - a busca dos documentos; b - as "ciências auxiliares"), ii) "Operações analíticas" (condições gerais do conhecimento histórico, crítica externa-crítica de erudição, crítica interna) e iii) "Operações sintéticas" (condições gerais da construção histórica, grupamento de fatos, raciocínio construtivo, construção de fórmulas gerais, exposição). Além disso, a obra apresenta dois apêndices sobre o ensino de História nas escolas e nas universidades na França.

Logo no início da obra, os historiadores franceses advertem, claramente, aos seus leitores de que não se trata de um resumo da história universal, nem de um texto sobre a Filosofia da História, "estas amplas construções abstratas caíram em descrédito" (LANGLOIS, 1946, p. 5-14.). Na verdade, ressaltam em várias partes do livro que "a melhor maneira de aprender a História é praticá-la”, ou seja, destacam a dimensão empírica e prática do conhecimento histórico. Nas suas palavras, propõem-se a "examinar as condições e os processos do conhecimento histórico, bem como indicarlhe o caráter e os limites". Trata-se, portanto, de um ensaio sobre o método das ciências históricas, pois “os processos racionais, que nos levam a atingir o conhecimento histórico são tão diferentes dos das demais ciências que devemos conhecer-lhes as peculiaridades, para fugirmos à tentação de aplicar à história os métodos das ciências já constituídas" (LANGLOIS, 1946, p.10).

Por isso, apresentam, em seu método histórico, as operações analíticas e sintéticas singulares da História. Em resumo, o plano da construção histórica com suas operações sintéticas, para Langlois e Seignobos, ocorre da seguinte maneira:

Pela análise crítica dos documentos conseguimos os materiais, que se nos
apresentam como fatos históricos ainda esparsos. Começamos por imaginá-
los, segundo o modelo de fatos atuais que julgamos análogos; procuramos, a
seguir pela combinação dos fragmentos apanhados em diversos lugares da
realidade, obter a imagem mais próxima da que teria sido gerada na
observação direta do fato passado. Depois agrupamo-los em quadros,
imaginados segundo o modelo de um conjunto dos fatos passados que nos
interessam. É a segunda operação; realizamo-la por meio de um questionário,
cujo escopo é discernir, na massa dos fatos históricos, episódios e fatos da

\footnotetext{
${ }^{8}$ A primeira metade do livro foi escrita por Langlois e a segunda por Seignobos.
} 
mesma natureza; agrupamo-los a seguir, entre si, até que toda a história do passado esteja classificada em um quadro universal. Depois de havermos extraído neste quadro os fatos extraídos dos documentos, verificamos que muitas lacunas existem, consideráveis sempre, mas enormes em relação às partes em que não há abundância de documentos. Tentamos, então, preencher algumas, por meio de raciocínios, construídos sobre fatos conhecidos. É a terceira operação; com ela se avoluma por um trabalho lógico, a massa dos conhecimentos históricos. Em seguida, devemos condensá-los em fórmulas e tentar destacar-lhes os caracteres gerais e as relações. É a quarta operação, ela nos conduz às conclusões últimas da história e coroa a construção histórica do ponto de vista científico (LANGLOIS, 1946, p. 159-160).

Além disso, como aborda Prost, Seignobos sublinhava o papel da imaginação ao fazer história; e tratava-se de um aspecto no qual ele insistia, energicamente, diante da emergência - ameaçadora para a história - da Sociologia (PROST, 2014, p. 170). Sua argumentação baseava-se em dois pontos essenciais: em primeiro lugar, todas as ciências sociais operavam "não sobre objetos reais, mas sobre as representações que temos dos objetos". As imagens é que constituíam a matéria concreta da ciência social; ao interessar-se pelos fatos do passado, a História não usufruía de qualquer status particular. Em segundo lugar, Seignobos avançava mais longe e chamava a atenção para o que, atualmente, seria traduzido nos seguintes termos: se pretendermos compreender os fatos humanos é impossível fazer abstração de seu sentido (PROST, 2014, p.170). Nas palavras de Seignobos:

\begin{abstract}
Enquanto matéria da ciência social, os atos humanos só podem, portanto, ser compreendidos por intermédio dos fenômenos conscientes do cérebro; assim, somos levados irresistivelmente à interpretação cerebral (ou seja, psicológica) dos fatos sociais. Auguste Comte havia acalentado a esperança de evita-la ao constituir a sociologia a partir da observação dos fatos externos que, afinal de contas, não passam de produtos dos estados internos. Estudá-los, isoladamente, sem conhecer os estados psicológicos que lhes servem de motivação, teria correspondido à pretensão de compreender os movimentos de um dançarino sem escutar a música que inspira sua dança (SEIGNOBOS, 1901, p. 109).
\end{abstract}

Em reação, os sociólogos saíram em defesa de Comte criticando essa visão. Como lembra Prost, para os sociólogos positivistas, a ciência social procede como todas as ciências; portanto, são obrigados a rechaçar Seignobos. Simiand foi quem exprimiu tal rejeição. Para ele, além de recusar a interpretação psicológica das condutas por motivações, ele pretere o que parece ser mais objetivo nos procedimentos dos historiadores, ou seja, seu modo de identificar o caráter único de um período - mais exatamente, de determinada sociedade em dado período - e mostrar os vínculos de interdependência que unificam todos os aspectos dessa sociedade nesse exato momento 
(PROST, 2014, p. 171). Em outras palavras, o próprio objetivo dos historiadores, ou seja, de compreender a originalidade de uma sociedade em seus diversos aspectos concordantes, implica em situar precisamente a originalidade de cada componente; ora, tal operação exige, em primeiro lugar, um estudo comparativo (PROST, 2014, p. 172).

Por outro lado, a proposição dos sociólogos positivistas rejeita a preocupação historizante com o concreto, que é sempre único. Ora, a ciência só pode ser feita a partir do geral, ou seja, do abstrato; assim, torna-se necessário construir fatos abstratos, sociais ou políticos - por exemplo, o absolutismo monárquico - para erigir a História como verdadeira ciência. Simiand, no entanto, não forneceu outro exemplo dos fatos sociais abstratos que, em seu entender, deveriam ser objeto de estudo para a História.

Jacques Le Goff, em A História Nova, destaca o papel de Simiand, apresentando-o como "um economista contra os ídolos dos historiadores" (LE GOFF, 1988, p. 41-42). Le Goff, na verdade, esforça-se em aproximá-lo ou ao menos vinculálo à História Nova. Em outras palavras, Simiand era tido por Le Goff como um mestre e aponta que os Annales se preocuparam com as críticas do sociólogo à História, tanto que tomaram como bandeiras necessárias a serem combatidas.

A década de 1920 foi marcada pelo movimento dos Annales. Da Universidade de Estrasburgo, em 1921, os historiadores Lucien Febvre (1878-1956) e Marc Bloch (1886-1944) fundaram a revista Annales d'Histoire Économique et Sociale. Bloch e Febvre teriam se insurgido contra um determinado modelo de pesquisa e escrita da História atribuída aos historiadores metódicos aglutinados em torno de professores da Sorbonne, como Gabriel Monod (1844-1912), Charles-Victor Langlois (1863-1929) e Charles Seignobos (1854-1942). Assim como Gabriel Monod e Langlois, Seignobos (membro da Liga dos Direitos Humanos), favorável aos republicanos, defendia o poder do Estado por ser republicano. Embora reconhecendo os méritos políticos de Seignobos, mas condenando à instrumentalização do seu ensino da História, os Annales combatem à História Política, erroneamente confundida com a História Nacional e a Históriabatalha (MALERBA, 2010, p. 381).

Nesse sentido, o comitê de direção simboliza a cooptação, dessa vez bemsucedida, das ciências sociais irmãs. Ao lado dos diretores, historiadores, notam-se as presenças do geógrafo vidaliano Albert Demangeon, do sociólogo durkheimiano Maurice Halbwachs, do economista Charles Rist, do politicólogo André Siegfried (DOSSE, 2001, p. 20). No entanto, isso terá um preço. Dosse lembra que o preço pago por esse sucesso, que logo vai transformar uma revista em escola, é o alinhamento da 
História com o programa durkheimiano assumido pelos historiadores. A revista dos Annales tem, então, um tom particularmente polêmico contra a chamada história historicizante, e Charles Seignobos, em especial, é atacado e ridicularizado em resenhas cáusticas: "Abro a História da Rússia: czares grotescos, saído do Ubu rei; tragédias palacianas; ministros concussionários; burocratas papagueadores; oukazes e prikazes à saciedade. Não, isso não é história... História é o que não encontro nessa História da Rússia, e por isso esta nasce morta”. (FEBVRE, 1953, p. 70-74). Seguindo com atraso a injunção de Simiand, nos Annales desaparece toda dimensão política da História, que praticamente não existe na revista. Ao contrário, o domínio econômico e social ocupa inteiramente o lugar da dimensão política. Em outras palavras, essa história poderia ser chamada sociológica, na medida em que assume as normas da sociologia durkheimiana e aplica métodos análogos.

René Rémond, por sua vez, ao falar de Charles Seignobos, destaca a sua reputação em parte injusta, sobretudo no que tange à História Política. Destaca:

Ele foi um dos primeiros a se da conta de dois fatos importantes cuja
constatação foi determinante nas origens da sociologia eleitoral: a
diversidade dos "temperamentos" políticos regionais e a antiguidade de seu
enraizamento. Seignobos acentuou a constância, na superfície do território,
da divisão direita-esquerda através das vicissitudes políticas, mudanças de
regime, flutuações aparentes da opinião pública. Por outro lado, seu livro,
hoje caído no esquecimento, sobre a história política da Europa, que
misturava um considerável volume de informações, era novo para a época
pelas possibilidades que oferecia de análises comparativas (RÉMOND, 2003,
p. 27).

Lembra Rémond: "nome de Seignobos, por exemplo, tornou-se, para uma geração que almejava fazer uma história das verdadeiras realidades, o próprio símbolo de uma história fora de moda." (RÉMOND, 2003, p. 44). Entretanto, observa-se que as contribuições de Seignobos, assim como de muitos outros pensadores do século XIX, foram e continuam sendo reflexões de grande valor tanto teórico-metodológico quanto historiográfico. Afinal de contas, como afirma Seignobos:

A história é também um elemento indispensável para o acabamento das ciências políticas e sociais, ainda em via de formação; porque a observação direta dos fenômenos sociais (em estado estático) não basta para constituir estas ciências; é preciso acrescentar-lhes o estudo do desenvolvimento desses fenômenos no tempo, isto é, sua história (LANGLOIS, 1946, p. 224). 


\section{Considerações finais}

Ao buscar traços e testemunhos acerca deste "polêmico" debate no início do século XX, observa-se certa injustiça em relação aos "metódicos", principalmente, por conta das críticas mais duras dos Annales. Nesse sentido, destaca-se que o maior legado deles foi a tentativa de afirmar o caráter científico da sua disciplina pela aplicação do método crítico e pelo estabelecimento dos fatos. No entanto, não foi isento de equívocos e discordâncias. A Sociologia, com François Simiand, se destacou com suas críticas.

De toda forma, é importante salientar que essa não foi a primeira "crise da História”, e nem será a última. Outras tensões, ao longo do século XX, marcaram as relações entre História e Sociologia. Destacamos por exemplo, um breve trecho de "História e Sociologia", capítulo do livro História e Ciências Sociais de Fernand Braudel (1982). Ao falar de Sociologia, em contraste com a História, Braudel ressalta que:

[...] se entende muito frequentemente por sociologia, essa ciência global que, nos princípios do século, Emile Durkheim e François Simiand dela aspiravam fazer; ciência que não é ainda, mas para que não deixará de tender, mesmo no caso de nunca chegar a sê-lo. Entendo por história uma investigação cientificamente conduzida, digamos, em rigor, uma ciência mais complexa. Não existe uma história, um ofício de historiador, mas sim ofícios, histórias, uma soma de curiosidades, de pontos de vista, de possibilidades; soma à qual no futuro, outras curiosidades, outros pontos de vista e outras possibilidades se virão ainda acrescentar. Talvez me faça compreender melhor por um sociólogo- que tende, como os filósofos, a ver na história uma disciplina de regras e métodos definidos com perfeição- se disser que existem tantas maneiras, de abordar o passado. Posto isto, que ninguém espere encontrar aqui uma resposta, nem sequer uma tentativa de resposta, às habituais perguntas sobre as relações entre história e sociologia ou uma continuação da polêmica, continuamente, retomada, ainda que não seja nunca a mesma, entre esses vizinhos que não podem ignorar-se nem conhecer-se perfeitamente $\mathrm{e}$ que, nas suas discussões, quando se definem, o fazem unilateralmente. Existem falsas polêmicas, tal como existem falsos problemas. Em todo caso, o diálogo do sociólogo e do historiador é quase sempre um falso diálogo (BRAUDEL, 1982, p. 69-70).

Ao contrário de Braudel, nota-se que, de fato, há certas polêmicas e certos problemas verdadeiros, e que devem ser enfrentados, tanto por historiadores como por sociólogos, mas não mais em um embate ferrenho e nocivo por espaços de poder, ou acadêmicos, mas, sim, por meio de uma reflexão e debate sadios. Para isso, talvez seja necessário reconhecer, mais uma vez, a História como uma ciência social, e, por sua vez, a ciência social como uma ciência histórica. Por fim, é necessário que a História e a Ciência Social aprofundem esse debate. Torna-se necessário retomar esse debate entre 
Seignobos e Simiand, deixando de lado certos dogmatismos, para melhor compreender os caminhos traçados por ambas disciplinas desde então. 


\section{REFERÊNCIAS}

BARROS, José D'Assunção. A Escola dos Annales e a crítica ao historicismo e ao positivismo. Revista Territórios e Fronteiras, Cuiabá, v. 3, n.1, p. 75-103, jan-jun 2010.

BRAUDEL, Fernand. História e Ciências Sociais. Tradução de Rui Nazaré. Lisboa: Editorial Presença; 1982.

DELACROIX, Christian; DOSSE, François; GARCIA, Patrick. As correntes históricas na França: séculos XIX e XX. Rio de Janeiro: FGV, 2012.

DOSSE, François. A história à prova do tempo: da história em migalhas ao resgate do sentido. Trad. Ivone Castilho Benedetti. São Paulo: Editora UNESP, 2001.

FEBVRE, Lucien. Combats pour l'Histoire. Paris: Armand Colin; 1953.

LANGLOIS, Charles-Victor; SEIGNOBOS, Charles. Introdução aos Estudos Históricos. Trad. Laerte de Almeida Morais. São Paulo: Renascença, 1946.

LE GOFF, Jacques (Org.). A História nova. Trad. Eduardo Brandão. $4^{\circ}$. Edição. São Paulo: Martins Fontes, 1988.

MALATIAN, Teresa. Um percurso historiográfico do conhecimento histórico. In: MALATIAN, Teresa. (Org.). Caderno de formação: conteúdos e didática de História. vol. 1. 1ed. São Paulo: Cultura Acadêmica, 2012. p. 61-68.

MALERBA, Jurandir (Org.) Lições de história: o caminho da ciência no longo século XIX. Rio de Janeiro: Editora FGV, 2010.

MARTINS, Estevão de Rezende (Org.). A História pensada: teoria e método na historiografia europeia do século XIX. São Paulo: Contexto, 2010.

NEVES, Guilherme Pereira das. Chegará o tempo da história? História da historiografia, Ouro Preto, n. 9, p. 222-245, 2012.

PROST, Antoine. Doze lições sobre a História. Trad. Guilherme João de Freitas Teixeira. 2 Ed. Belo Horizonte: Autêntica Editora, 2014.

RÉMOND, René (Org.). Por uma história política. 2 ed. Rio de Janeiro: Editora FGV, 2003.

SEIGNOBOS, Charles. La méthode historique apliquée aux sciences sociales. Paris: F. Alcan, 1901. Disponível em: $<$ http://classiques.uqac.ca/classiques/seignobos_charles/Methode_historique_appliquee _aux_sc_soc/Methode_historique_appliquee_aux_sc_soc.pdf >. Acesso em: 05 out. 2016. 
SILVA, Brunno Hoffmann Velloso. Encontros entre História e Sociologia: primeiros embates metodológicos na França. História e Cultura, Franca, v. 3, n. 3 [Especial], p. 7-27, dez. 2014.

SILVA, Helenice Rodrigues da. Charles Seignobos. In: MALERBA, Jurandir (Org.). Lições de história: o caminho da ciência no longo século XIX. Rio de Janeiro: Editora FGV, 2010.

SIMIAND, François. Método histórico e ciência social. Trad. José Leonardo do Nascimento. Bauru: Ed. EDUSC, 2003.

SIMIAND, François. Méthode historique et Science sociale. Revue de synthèse historique, 1903. [retomado in Annales ESC, 1960]. Disponível em: <http://classiques.uqac.ca/classiques/simiand_francois/methode/methode_12/methode_ hist_sc_soc2.html>. Acesso em: 03 dez. 2016.

SIMIAND, François. Note de méthode: Sur la notion de cause en matière historique et sociologique. Notes critiques/Sciences Sociales, Paris, v. 4, p. 129-132, 1903 b. Disponível em: $<$ http://classiques.uqac.ca/classiques/simiand_francois/methode/methode_14/notion_his t_socio.html . Acesso: 03 dez. 2016. 